\title{
Delivering Good Service: Personal Resources, Job satisfaction and Nurses' 'Customer' (Patient) Orientation
}

\begin{abstract}
Aims. To explore the complex relationships between nurses' personal resources, job satisfaction and 'customer' (patient) orientation.
\end{abstract}

Background. Previous research has shown that nursing is highly intensive, emotionally charged work which affects nurses' job performance and their customer orientation as well as patient or 'customer' satisfaction. This study contributes to the literature by examining how nurses' personal resources relate to their personal satisfaction and customer orientation and the relationships between them. Specifically, this study explores the effects of two facets of emotional labour (deep acting and surface acting), empathic concern, self-efficacy and emotional exhaustion on personal job satisfaction and customer orientation. We also test the moderating effects of inauthenticity and emotional contagion.

Design. A quantitative survey.

Method. Data were collected through a self-completion questionnaire administered to a sample of 159 Australian nurses, in a public teaching hospital, in 2010. The data were analysed using Partial Least Square analysis.

Results. Partial Least Square analysis indicates that the final model is a good fit to the data $($ Goodness of Fit $=0.51)$. Deep acting and surface acting have different effects (positive and negative) on job satisfaction and 'customer' orientation, self-efficacy has a positive effect on both and emotional exhaustion has a positive effect on customer orientation and a negative effect on job satisfaction. The moderating effects of emotional contagion and empathic concern, in the final model, are discussed.

Conclusions. Understanding the complex interactions between personal resources, job satisfaction and customer orientation helps to increase service providers' (nurses in this study) personal satisfaction and 'customer' orientation particularly in difficult contexts. 
Key Words: Nurses’ Satisfaction, 'Customer' (Patient) Orientation, Emotional Labour, Personal Resources.

\section{SUMMARY STATEMENT}

\section{Why is this research needed?}

- The study examines the role of personal resources: self-efficacy, emotional exhaustion and emotional labour, empathy, and emotional contagion and shows how these directly affect, interact or intervene with job satisfaction and 'customer' orientation, in nurses, when tested simultaneously in WarpPLS.

- Most studies show the total effect of emotional labour in nursing; this study discretely tests the effects of two key facets of emotional labour: deep acting and surface acting.

\section{What are the Key Findings?}

- Emotional exhaustion has a negative relationship with job satisfaction but a positive relationship with customer orientation. Also, deep acting and surface acting have different, positive and negative effects on job satisfaction and customer orientation.

- Self-efficacy has a positive relationship with job satisfaction and customer orientation.

- The model suggests moderating effects of empathic concern and emotional contagion in the relationships between job satisfaction and customer orientation and emotional exhaustion and customer orientation. The results show that job satisfaction mediates the relationship between personal resources and customer orientation.

\section{How should the findings be used to influence policy/practice/research/education?}

- This research highlights the need for managers to understand the complex relationships and interactions between personal resources, job satisfaction and customer orientation, explored in this study. 
- The results suggest that training and appropriate management can help to enhance personal resources and reduce negative effects of emotion work on job satisfaction and customer orientation.

\section{INTRODUCTION}

Nursing is a high involvement service profession and patients are increasingly seen as 'clients' or 'customers' (Hudak et al. 2003). Consequently, an understanding of nurses' 'customer' (patient) orientation is likely to be useful to healthcare managers, as appropriate and caring interactions between nurses and patients (service providers and recipients) are essential to customer (patient) satisfaction (Susskind et al. 2003). In a broader services marketing context, a service worker's customer orientation has been suggested to be a predisposition to care for customers' needs (Brown et al. 2002, Skalen 2009), and this fits well within the nursing profession. A person's customer orientation is an attitudinal variable that has a direct effect on that person's overall performance, customer oriented behaviours and commitment (Grizzle et al. 2009, Stock \& Hoyer 2005). Additionally, a person's customer orientation affects customers' satisfaction, which is important, particularly in a credence service such as nursing (Darby \& Daniel 1999). Credence services are defined as having attributes that are difficult for the consumer to evaluate before the service, and often even after the service has occurred (Darby \& Karri 1973). The difficulty in evaluating the service is usually due to the consumer's lack of knowledge, understanding and expertise which is most often the case in health services (Dagger \& Sweeney 2007, Prenshaw et al. 2006).

Customer orientation is also associated with job satisfaction. Many studies have found job satisfaction leads to better performance and that good job performance leads to job satisfaction. However, the causes of job satisfaction are many and individual states, such as happiness and well-being, may have a stronger direct effect on job performance than job 
satisfaction (Wright \& Cropanzano 2000). This is important, as nurses' performance and job satisfaction are affected by the emotional nature of their work and their need to control the ways in which they express or supress their emotions (Bartram et al. 2012). Therefore, a better understanding of how nurses' personal (psychological) resources contribute to job satisfaction should help nursing managers make work organisational decisions that benefit customers (patients in this case) and services providers (nurses in this case).

Nurses' job satisfaction reduces the effects of negative emotion work (Yang \& Chang 2008), and, therefore, should be a major concern; particularly when there are problems in recruiting and retaining nurses. Indeed, research suggests that nurses' job satisfaction may affect the whole nursing workforce (Lu et al. 2005). For example, the result of nurses' dissatisfaction can be seen in recent industrial action in countries such as Australia and the United Kingdom. Consequently, the study discussed here was undertaken to explore the roles that nurses' personal resources (individual emotional states and self-efficacy) play and to examine the effects these have on nurses' job satisfaction and customer orientation.

\section{BACKGROUND}

Nursing is a stressful occupation because it is emotionally demanding as it involves dealing with patients' problems and suffering. Nurses need to manage stress related negative emotions for their own well-being and if they are to provide good patient care. In recent years, a conceptual shift in thinking about patients as 'customers' has resulted in a focus on nurses needing to develop a customer orientation, similar to that needed in most other service industries (Hudak et al. 2003). This shift may have occurred due to the nature of health care services. Nursing is a credence service and as patients' generally cannot assess the technical side of their treatment, they tend to assess the service process and the people providing it, 
primarily nurses, as they are the major point of contact (Dagger \& Sweeney 2007, Prenshaw et al. 2006, Darby \& Daniel 1999).

Medical services managers need to pay greater attention to the conditions that support nurses' customer orientation; in particular nurses' emotional labour (Bakker et al. 2005), which is particularly high in nursing (Yang \& Chang 2008). An additional concern is that people engaged in emotional labour are expected to appear authentic, which may lead to acting to achieve the desired impression, resulting in deleterious effects to the service provider's own health (Hochschild 1983, Erickson \& Wharton 1997). The key processes of emotional labour are surface acting and deep acting. Surface acting involves the inauthentic modification and control of emotional expressions, such as faking a smile or being pleasant when one is in a bad mood, which can have negative effects on both patients (customers) and nurses (service providers). Deep acting requires an authentic change of mood and expression, which can have positive benefits for both the sender and receiver (Brotheridge \& Grandey 2002).

Although, the need for emotion management is generally accepted in nursing and other services, acting in an inauthentic way can have negative effects on workers, including burnout, low satisfaction and depression (Erickson \& Wharton 1997). Conversely, authenticity in the work place is associated with better job performance and greater job satisfaction and is thought to influence the relationship between work conditions and performance outcomes (van den Bosch \& Taris 2013). Therefore, feelings of personal inauthenticity are likely to have a negative effect on performance related conditions such as attempts to appear authentic and empathic concern. However, the effects of emotion management and inauthenticity differ in different individuals, with some people being unaffected (Sloan 2007). This suggests that inauthenticity may moderate the effects of other personal resources and characteristics on job satisfaction and performance. 
The concept of authenticity extends beyond the individual to an organisational level of 'climate' of authenticity. In an authentic climate, people feel able to express their emotions without fear of negative ramifications. This leads to trust and perceived safety and these conditions ameliorate negative effects of emotional labour and job stress (Grandey et al. 2012). Each person's evaluation of their workplace situation is influenced by their susceptibility to emotional contagion, or 'catching' others' emotions and their ability to tune into others. In the worst case, emotional contagion may mean service providers 'catch' negative emotions from co-workers and patients, which negatively affects their satisfaction and well-being (Bakker et al. 2005). A positive, supportive working environment is likely to reduce negative emotional contagion effects and is associated with positive outcomes such as satisfaction and superior performance (Fawzi AbuAlRub 2004, Omdahl \& O’Donnell 1999).

Emotional contagion can also have positive effects. For example, emotional contagion is related to empathy and this has been shown to have positive effects on patients' perception of care received and well-being (Williams \& Stickley 2010). Empathy has long been considered a fundamental component of good nursing care, as it is key to trust-building and the creation of an effective therapeutic relationship between healthcare providers and patients (Williams \& Stickley 2010, Brunero et al. 2009). The empathic concern shown by service providers contributes to customer satisfaction, improves providers' communicative responsiveness and may avert emotional exhaustion in some, benefitting service providers and recipients (Omdahl \& O'Donnell 1999). On the other hand, a lack of empathic concern causes some people to suffer distress and increased work stress as a result (Lopez-Perez et al. 2013).

Whether the effects of emotion work are generally positive or negative, direct or indirect depends on a number of factors, such as workers' personal dispositions, autonomy at work and the stress connected with job roles (Garrosa et al. 2011, Grandey 2000, Wharton 1993). 
Many studies have shown workplaces conditions can have negative consequences, such as job stress and low job satisfaction. However, personal evaluations of stress and satisfaction may mean the consequences of emotional labour are not always deleterious. Research indicates that emotional labour may increase job satisfaction and feelings of personal accomplishment, for some, which reduces negative effects, such as emotional exhaustion (Seery \& Corrigall 2007, Pugliesi 1999). In some situations, workers may gain satisfaction from improving others' emotional well-being and receiving appreciation for their efforts (Bakker et al. 2004, Seery \& Corrigall 2007, Kiffin-Petersen et al. 2012), which may increase self-efficacy perceptions.

Many studies have also found a relationship between job satisfaction, self-efficacy and performance outcomes (Judge et al. 2007). An increase in self-efficacy appears to increase employees' effort and subsequent job performance (Hartline \& Ferrell 1996). Workers high in self-efficacy tend to use problem solving coping strategies, while workers low in self-efficacy are more prone to anxiety and operate on a more emotional level (Jex \& Bliese 1999), which may increase stress, reduce job satisfaction and suggest a greater need for organisational support.

Job satisfaction is a set of feelings people have about their jobs. It is also a person's affective and cognitive evaluation of what job conditions should be and what they are perceived to be, which affects future expectations ( $\mathrm{Lu}$ et al. 2005). Considerable research has examined the relationship between job satisfaction and performance (Aronson et al. 2005). However, findings are inconsistent, as some studies supported this relationship, while others did not (Judge et al. 2001). It seems the relationship depends on job context and may be influenced by job complexity and personal disposition (Judge et al. 2001). In nursing, job satisfaction seems to be related to work performance and associated with good patient care ( $\mathrm{Lu}$ et al. 
2005). These are important factors to consider, as the consequences of emotional labour and exhaustion may affect nurses' job satisfaction and general life satisfaction (Demerouti et al. 2000).

Consequently the present study explores a) the direct relationships between emotional states, personal resources and job satisfaction and customer orientation b) the mediating effect of job satisfaction and c) moderating effects of emotional contagion and inauthenticity. A conceptual model (Figure 1) based on the prior research discussed earlier was developed to consider the following questions;

(1) What effects do emotional states and personal resources (emotional labour, selfefficacy, emotional exhaustion and empathic concern) have on job satisfaction and customer (patient) orientation?

(2) What is the relationship between nurses' job satisfaction and customer (patient) orientation?

(3) In accordance with the literature, does job satisfaction mediate the relationship between personal resources and the performance outcome such of customer orientation?

(4) Does emotional contagion moderate the relationships between deep acting, surface acting, self-efficacy and job satisfaction and customer (patient) orientation?

(5) Does inauthenticity moderate the relationships between surface acting, empathic concern, emotional exhaustion and job satisfaction and customer (patient) orientation?

The study examining this model, results and their implications are discussed in the following sections. 


\section{THE STUDY}

\section{Aim}

The aim of this study is to explore the relationships indicated in the conceptual model.

\section{Design}

A quantitative study conducted using self-completion questionnaires.

\section{Participants}

Five hundred questionnaires were distributed to nurses who were working at an Australian public teaching hospital at the time of data collection in 2010. The data collection took place during a difficult period when nursing staff spoke of their concern that hospital facilities and resources were inadequate to service the increasing needs of the local population. Indeed, some expressed concern for patient care and safety.

\section{Data collection}

One hundred and fifty nine nurses $(32 \%)$, in one public teaching hospital, responded to the self-completion questionnaire providing the data used in the present study. The questionnaire took approximately 15 minutes to complete and participation was voluntary and anonymous. Most of the respondents (62\%) were between 36 - 50 years of age; $60 \%$ had supervisory roles, $74 \%$ have been working for more than five years in healthcare and $22 \%$ were males, which is representative of the nursing population that was surveyed.

\section{Measures}

The study uses the following validated measures to explore the conceptual model (Figure 1). Prior to finalising the questionnaire, we consulted six unit managers and education providers 
at the hospital to ensure that the items comprising the chosen measures were representative of the constructs. Items, in each scale, were adapted to suit the nursing context, where necessary, by substituting the word 'customer' for 'patient'. Responses were measured on a seven-point Likert-type scales that ranged from strongly disagree (1) to strongly agree (7);

1. Job Satisfaction was measured using eight items that asked about satisfaction with personal opportunities, organisational issues, support and salary (Brown \& Peterson 1993). Items include "Overall, I am satisfied with this job" and "I am satisfied with the support provided in my job".

2. Customer Orientation was measured using five items that asked about attitudes towards customers (Susskind et al. 2003). For example, “As an employee responsible for providing service, patients are very important to me" and "If possible, I meet all requests made by my patients".

3. Emotional Exhaustion was measured using six items that asked about burn out, frustration and a dread of going to work (Wharton 1993). For example, "I feel frustrated by my job" and "I feel burned out from my work".

4. Employee Self-Efficacy was measured using eight items that asked about capability and confidence (Jones 1986). Items include "Professionally speaking, my job exactly satisfies my expectations of myself" and "My job is well within the scope of my abilities".

5. Empathic concern was measured using seven items that asked about concern for others (Davis 1983). Item include “Sometimes I don’t feel very sorry for other people when they are having problems" (reversed) and "I would describe myself as a pretty soft-hearted person". 
6. Emotional labour was measured using ten items that asked about emotional responses to people work (Brotheridge \& Grandey 2002) that formed four subscales (variety, intensity, deep acting and surface acting), although only the deep acting and surface acting subscales were used in the present study. For example, "I make an effort to actually feel the emotions that I need to display to others" and "I pretend to have emotions that I don't really have in my job".

7. Emotional Contagion was measured using seven items that asked about 'catching' other peoples' emotions (Stiff et al. 1988). For example, "I often find that I can remain cool in spite of the excitement around me"; "I tend to lose control when I am bringing bad news to people".

8. Inauthenticity was measured using six items examining authenticity at work (Sloan 2007). For example, "Basically, I have to become a different person when I am at work" and "I worry that this job is hardening me emotionally".

\section{Ethical considerations}

Ethics approval was obtained from both the university and hospital involved in the study.

\section{DATA ANALYSIS}

Given the sample size (159), we decided to use a partial least squares (PLS) approach to estimate the model. In this case, the Partial Least Squares (PLS) regression procedure within the WarpPLS 3.0 software program (Kock 2012) was used to estimate the model.

Partial Least Squares (PLS) is a particularly useful approach when samples are smaller than is desirable for covariance-based approaches, such as LISREL or AMOS. WarpPLS uses a bootstrapping approach that reduces the concern about the distributional properties of the data being used to estimate a model (Kock 2012). The model, shown in Figure 1, was estimated using the WarpPLS 3.0 software program. WarpPLS identifies non-linear or 'warped' 
relationships, including moderating and mediating effects simultaneously and adjusts the values of path coefficients accordingly. Since many behavioural variables are complex and non-linear in nature, this is a very useful way of estimating them. Using WarpPLS means that 'true', complex relationships between variables in Structural Equation Model analysis are examined (Kock 2011, Kock 2010). Also, it is often difficult to obtain large datasets in the working environment but as WarpPLS identifies non-linear relationships it can be used successfully to analyse small samples.

While PLS models do not have the range of goodness of fit measures suggested for covariance-based procedures, Tenenhaus et al. (2005) suggest a goodness of fit (GOF) index, which is computed as the square root of the average variance extracted score for the model's constructs and the average R-squared for all of the endogenous constructs. Wetzels et al. (2009) suggest a GOF value of 0.36 implies there would be large effect sizes within the model and that the model performs well. In this case the GOF value was 0.51 , suggesting it was worth examining the model in detail.

\section{RESULTS}

\section{Validity and Reliability}

Table 1 shows the means (M), standard deviations (SD), composite reliability (CR) scores Cronbach's Alpha scores (CA), average variance extracted (AVE) score and inter-correlations for the constructs included in the study. All of the scales are reliable, as the composite reliability scores are above 0.78 and the Cronbach's Alpha scores above 0.65 and all of the constructs have convergent validity, as the AVE scores all exceed 0.50 (Fornell \& Larcker 1981). Further, all of the constructs have discriminant validity, as the AVE scores are greater than the highest squared correlation between any two constructs (Fornell \& Larcker 1981). 
Consequently, the constructs all have robust measurement properties and may be used with confidence in estimating the model.

The mean scores suggests that, on average, respondents are not very likely to engage in either deep acting or surface acting behaviours or to suffer from emotional exhaustion, as these means are below the midpoint of the seven-point scale. Further, the nurses, on average, have strong empathic concern, are satisfied with their job and have a positive customer orientation, as all of these means are well above the midpoint of the seven-point scale. All of the constructs have reasonable standard deviations (ranging from 0.71 to 1.51 ), suggesting there is enough variation in the data to make it useful to estimate the suggested model.

\section{Estimating the Model}

Not all of the model's (Figure 1) relationships are significant. In particular, the path from deep acting to job satisfaction and the two paths from empathic concern are not significant. The latter result suggests empathic concern is not an antecedent and that it may be excluded from the analysis. It is clear job satisfaction has the greatest direct effect on customer orientation. Deep acting does not have a significant effect on job satisfaction, but surface acting has a negative effect. Deep acting is negatively related to customer orientation while surface acting is positively related. Emotional exhaustion is also positively related to customer orientation, and negatively related to job satisfaction. Employee self-efficacy is positively related to both job satisfaction and customer orientation.

\section{The Moderating Effects}

As indicated in the conceptual model in Figure 1, potential moderators, emotional contagion and inauthenticity, were examined because past research suggests such effects may be present. 
However, of these two, only emotional contagion has a moderating effect on the relationship between emotional exhaustion and customer orientation. When emotional contagion is low, the relationship between emotional exhaustion and customer orientation is not significant. However, when emotional contagion is high the relationship between emotional exhaustion and customer orientation is significant. This suggests the higher a nurse's susceptibility to emotional contagion, the stronger the negative relationship between emotional exhaustion and customer orientation.

As empathic concern does not have the expected direct effects on job satisfaction and customer orientation, we decided to test for moderating effects as the literature indicates the importance of empathy in health care services. The interaction between empathic concern and job satisfaction on customer orientation is significant. When a nurse's empathic concern is low, the relationship between job satisfaction and customer orientation is significant. However, while the relationship between job satisfaction and customer orientation is still significant when a nurse's empathic concern is high, it is not as strong, suggesting the higher a nurse's empathic concern the weaker the relationship between job satisfaction and customer orientation. These effects should be considered as the $\mathrm{R}^{2}$ statistic for the dependent variable, customer orientation, increased from 0.40 to 0.52 when empathic concern and emotional contagion were included in the model.

\section{Job Satisfaction as a Mediator}

As can be seen in Figure 2, job satisfaction is modelled as a mediator between the other antecedent constructs and customer orientation. The role of job satisfaction as a mediator is assessed using the approach suggested by Preacher and Hayes (2004), as WarpPLS provides standard errors from the bootstrapping procedures used to estimate the model's parameters. That is the indirect effects' confidence intervals are computed and, if they do not contain zero, 
the indirect effects are assumed to be significant. Further, if the direct effects of the antecedent constructs are not significant, full mediation is assumed, while, if the direct effects are still significant, partial mediation is assumed. As shown in Table 2, job satisfaction partially mediates the relationships between surface acting, self-efficacy and emotional exhaustion and customer orientation. However, job satisfaction is not a mediator of the relationship between deep acting and customer orientation. When job satisfaction is not included in the model, the variation in customer orientation $\left(\mathrm{R}^{2}\right.$ statistic) falls to 0.23 , suggesting job satisfaction does play a mediating role and that it should be modelled in this way.

\section{DISCUSSION}

The aim of the present study is to investigate the complex relationships between nurses' personal resources, job satisfaction and 'customer' (patient) orientation by examining the complex effect that aspects of nurses' psychological condition (surface acting, deep acting, self-efficacy, empathic concern and emotional exhaustion) have on job satisfaction and customer orientation. Emotional labour affected job satisfaction and customer orientation, as has been found in prior research (Bartram et al. 2012). However, this study distinguished between deep acting and surface acting and found these aspects have different effects which are an important finding. Deep acting had a negative association with customer orientation, while surface acting had a small, but positive association with customer orientation. Interestingly, this was reversed in the relationship with job satisfaction. Deep acting does not relate to job satisfaction but surface acting has a negative association with job satisfaction. This finding offers a valuable distinction between two aspects of emotional labour, which may be due to the effort required to achieve a genuine state of deep acting, while surface acting indicates a nurse is making an effort and is concerned about the customer, but may be 
emotionally detached and better protected from the deleterious effects of emotion work. Deep acting relates to authenticity and although inauthenticity, as a discrete measure, does not play a role in this research, we believe that it is important and should be further explored utilising a measure specifically validated for the workplace such as that developed by van den Bosch and Taris (2013).

As expected, emotional exhaustion affects job satisfaction and customer orientation. The negative relationship with job satisfaction and the positive relationship with customer orientation seem contradictory, but may be explained by nurses' personal interpretations of a stressful work role and pressured situations, resulting in greater concern for patients at the same time as a reduction in personal job satisfaction. The findings suggest emotional contagion moderates the relationship between emotional exhaustion and customer orientation. It seems susceptibility to emotional contagion may have positive and negative consequences for outcomes such as job satisfaction and customer orientation. Perhaps, those prone to 'catching' others' emotions are particularly vulnerable during difficult times, such as those noted at the time of data collection. As mentioned earlier, the study took place during a difficult time in management and staff relations at the hospital and this may have further exacerbated the negative effect of susceptibility to emotional contagion.

Self-efficacy has a positive relationship with job satisfaction and customer orientation, suggesting that, as in previous research, self-efficacy has a positive effect on effort, job satisfaction and ability to cope with stress (Spence Laschinger \& Grau 2011, Jex \& Bliese 1999). This is important as although self-efficacy is an individual trait, it can be increased through positive organisational culture and values as well as efficacy training (Gountas et al. 2013). 
Empathic concern seems to reduce the strength of the relationship between job satisfaction and customer orientation in this study. This is consistent with research that has shown highly empathic staff may have difficulty in maintaining an objective perspective, which increases their personal stress. However, low empathy may negatively affect patients (customers) (Lopez-Perez et al. 2013). Some studies suggest empathy education may have a positive effect on participating nursing staff and even their colleagues who do not receive the training which may be due to the contagious nature of empathy (Herbek \& Yammarino 1990). Further research towards a greater understanding of these complex relationships is encouraged.

\section{Limitations}

The key limitation of this study lies in the small sample, which was drawn from one hospital. However, these are interesting results which contribute new insights. Therefore, the model should be tested more widely in future across different organisations and services. For example, an ideal scenario would be to test the model with larger samples in three or more hospitals and across different healthcare functions. As with all questionnaires completed by the same individuals, common method variance may be an issue. However, this should be minimized as well established measures were used and the correlations between measures were not excessively high (Spector 2006).

\section{Conclusions and Implications}

There are many associations between a service providers' psychological state and their interactions with other service providers and consumers. Further research would help to increase our understanding of the complex issues found in highly stressful service work such as nursing. Individual emotional states and coping abilities can be characterised as psychological capital that, when high, buffers the negative effects of work stress and exhaustion (Spence Laschinger \& Grau 2011). 
This paper suggests personal resources have subtle complexities that may be associated with individual differences, organisational culture and management; and have implications for nursing staff education, training and support. The results have implications for management in health care provision and in other services that are high in emotional labour and stress. Clearly, it is important to recognise that there are differences in people's attitudes and responses to stressful situations that result in different outcomes and some individuals are better able to protect themselves. All of this supports the notion that an ability to manage emotions and interactions with customers and co-workers is an individual trait that can be assisted through appropriate training and the development of a positive organisational climate (Lopez-Perez et al. 2013, Brunero et al. 2009, Herbek \& Yammarino 1990; Grandey et al. 2012). This is crucial research as it indicates the importance of a positive organisational culture and work environment for nurses' job satisfaction which, in turn, affects patients' satisfaction (Garcia-Garcia et al. 2011, Tzeng et al. 2002).

Exploring different ways to ameliorate problems through adjustments to existing training and work processes should increase nurses' psychological well-being and positively affect both nurses and patients. 


\section{REFERENCES}

Aronson KR, Laurenceau JP, Sieveking N \& Bellet W (2005) Job Satisfaction as a Function of Job Level. Administration and Policy in Mental Health 32, 285-290.

Bakker AB, Demerouti E \& Verbeke W (2004) Using the Job Demands-Resources Model to Predict Burnout and Performance. Human Resource Management 43, 83-104.

Bakker AB, Le Blanc PM \& Schaufeli WB (2005) Burnout contagion among intensive care nurses. Nursing Theory and Concept Development and Analysis 51, 276-287.

Bartram T, Casimir G, Djurkovic N, Leggat SG \& Stanton P (2012) Do perceived high performance work systems influence the relationship between emotional labour, burnout and intention to leave? A study of Australian nurses. Journal of Advanced Nursing 68, 1567-1578.

Brotheridge CM \& Grandey AA (2002) Emotional Labour and Burnout: Comparing Two Perspectives of People Work. Journal of Vocational Behaviour 60, 17-39.

Brown SP \& Peterson AA (1993) Antecedents and Consequences of Salesperson Job Satisfaction: Meta-Analysis and Assessment of Causal Effects. Journal of Marketing Research 30, 63-77.

Brown TJ, Mowen J, Donovan DT \& Licata JW (2002) The Customer Orientation of Service Workers: Personality Trait Effects on Self and Supervisor Performance Ratings. Journal of Marketing Research 39, 110-119.

Brunero S, Lamont S \& Coates M (2010) A review of empathy education in nursing. Nursing Inquiry 17, 65-74.

Dagger TS \& Sweeney JC (2007). How do Novice and Longer-Term Customers Construct Service Quality Perceptions? Journal of Service Research 10, 22-42.

Darby DN \& Daniel K (1999) Factors that influence nurses' customer orientation. Journal of Nursing Management 7, 271-280.

Davis MH (1983) Measuring individual differences in empathy: Evidence for a multidimensional approach. Journal of Personality and Social Psychology 44, 113-126.

Demerouti E, Bakker AB, Nachreiner F \& Schaufeli WB (2000) A model of burnout and life satisfaction amongst nurses. Journal of Advanced Nursing 32, 454-464.

Duffy MK, Ganster DC \& Pagon M (2002) Social Undermining in the Workplace. The Academy of Management Journal 45, 331-351.

Erickson J \& Wharton AS (1997) Inauthenticity and depression: assessing the consequences of interactive service work. Work and Occupations 24, 188-214.

Fawzi AbuAlRub R (2004) Job Stress, Job Performance, and Social Support Among Hospital Nurses. Journal of Nursing Scholarship 36, 73-78. 
Fornell C \& Larcker DF (1981) Evaluating structural equation models with unobservable variables and measurement error. Journal of Marketing Research 18, 39-50.

Garcia-Garcia I, Benitez Ramos V, Cobos Serrano JL, Ramos Cobos MC \& Souza A (2011) Nursing personnel's perceptions of the organizational climate in public and private hospitals on Spain. International Nursing Review 234-241.

Gountas S, Gountas J \& Mavondo FT (2013) Exploring the associations between standards for service delivery (organisational culture), co-worker support, self-efficacy, job satisfaction and customer orientation in the real estate industry. Australian Journal of Management DOI:10.1177/0312896212468453 (Accessed 15 January 2013).

Garrosa E, Moreno-Jimenez B, Rodriguez-Munoz A \& Rodriguez-Carvajal R (2011) Role stress and personal resources in nursing: A cross-sectional study of burn-out and engagement. International Journal of Nursing Studies 48, 479-489.

Grandey AA (2000) Emotion Regulation in the Workplace: A New Way to Conceptualize Emotional Labour. Journal of Occupational Health Psychology 5, 95-110.

Grandey AA, Foo SC, Groth M \& Goodwin RE (2012) Free to be you and Me: A Climate of Authenticity Alleviates Burnout From Emotional Labour. Journal of Occupational Health Psychology 17, 1-14.

Grizzle JW, Zablah AR, Brown TJ, Mowen JC \& Lee JM (2009) Employee Customer Orientation in Context: How the Environment Moderates the Influence of Customer Orientation on Performance Outcomes. Journal of Applied Psychology 94, 1227-1242.

Hartline MD \& Ferell OC (1996) The Management of Customer-Contact Service Employees: An Empirical Investigation. Journal of Marketing 60, 52-70.

Herbek FJ \& Yammarino FJ (1990) Empathy Training for Hospital Staff Nurses. Group and Organization Studies 15, 279-295.

Hochschild AR (1983) The Managed Heart: Commercialization of Human Feeling, University of California Press, Berkeley, CA.

Hudak, PL, McKeever P \& Wright JG (2003) The metaphor of patients as customer: Implications for measuring satisfaction. Journal of Clinical Epidemiology 56, 103-108.

Jex SM \& Bliese PD (1999) Efficacy Beliefs as a Moderator of the Impact of Work-Related Stressors: A Multilevel Study. Journal of Applied Psychology 84, 349-361.

Jones GR (1986) Socialization Tactics, Self-Efficacy and Newcomers' Adjustments to Organizations. Academy of Management Journal 29, 262-79.

Judge TA, Thoresen CJ, Bono JE \& Patton GK (2001) The Job Satisfaction-Job Performance Relationship: A Qualitative and Quantitative Review. Psychological Bulletin 127, 376-407.

Judge TA, Jackson CL, Shaw JC, Scott BA \& Rich BL (2007) Self-Efficacy and Work Related Performance: The Integral Role of Individual Differences. Journal of Applied Psychology 92, 107-127. 
Kiffin-Petersen S, Murphy SA \& Soutar G (2012) The problem-solving service worker: Appraisal mechanisms and positive affective experiences during customer interactions Human Relations 65, 1179-1206.

Kock N (2012) WarpPLS 3.0 User Manual, ScriptWarp Systems, Laredo, TX.

Kock N (2011) Using WarpPLS in e-Collabouration Studies: Mediating Effects, Control and Second Order Variables, and Algorithm Choices. International Journal of e-Collaboration 7 , $1-13$.

Kock N (2010) Using WarpPLS in e-Collabouration Studies: An Overview of Five Main Analysis Steps. International Journal of e-Collaboration 6, 1-11.

Lopez-Perez B, Ambrona T, Gregory J, Stocks E \& Oceja L (2013) Feeling at hospitals: Perspective-taking, empathy and personal distress among professional nurses and nursing students. Nurse Education Today http://dx.doi.org/10.1016/ j.nedt.2013.01.010 (accessed 05 April 2013).

Lu H, While AE \& Barriball KL (2005) Job satisfaction among nurses: a literature review. International Journal of Nursing Studies 42, 211-227.

Omdahl BL \& O’Donnell C (1999) Emotional contagion, empathic concern and communicative responsiveness as variables affecting nurses' stress and occupational commitment. Journal of Advanced Nursing 29, 1351-1359.

Preacher KJ \& Hayes AF (2004) SPSS and SAS procedures for estimating indirect effects in simple mediation models. Behavior Research Methods, Instruments, and Computers 36, 717 731.

Prenshaw PJ, Kovar SE \& Gladden Burke K (2006) The impact of involvement on satisfaction for new, non-traditional, credence-based service offerings. Journal of Services Marketing 20, 439-452.

Pugliesi K (1999) The Consequences of Emotional Labour: Effects on Work Stress, Job Satisfaction and Well Being. Motivation and Emotion 23, 125-154.

Seery BL \& Corrigall EA (2009) Emotional labour: links to work attitudes and emotional exhaustion. Journal of Managerial Psychology 24, 797-813.

Skalen P (2009) Service marketing and subjectivity: The shaping of customer-oriented proactive employees. Journal of Marketing Management 25, 795-809.

Spector PE (2006) Method variance in organizational research: truth or urban legend? Organizational Research Methods 9, 221-232.

Spence Laschinger HK \& Grau AL (2011) The influence of personal dispositional factors and organizational resources on workplace violence, burnout, and health outcomes in new graduate nurses: Across-sectional study. International Journal of Nursing Studies 49, $282-$ 291. 
Sloan MM (2007) The "Real" Self and Inauthenticity: The Importance Self-Concept Anchorage For Emotional Experiences in the Workplace. Social Psychology Quarterly 70, 305-318.

Stiff JB, Dillard JP, Somera L, Kim H \& Sleight C (1988) Empathy, Communication and Prosocial Behavior. Communication Monographs 55, 198-213.

Stock RM \& Hoyer WD (2005) An Attitude-Behaviour Model of Salespeople's Customer Orientation. Journal of the Academy of Marketing Science 33, 536-171.

Susskind AM, Kacmar KM \& Borchgrevink CP (2003) Customer Service Providers' Attitudes Relating to Customer Service and Customer Satisfaction in the Customer-Server Exchange. Journal of Applied Psychology 88, 179-187.

Tae WL \& Yu KK (2010) Effects of self-efficacy, affectivity and collective efficacy on nursing performance of hospital nurses. Journal of Advanced Nursing 66, 839-848.

Tenenhaus M, Esposito Vinzi V, Chatelin YM \& Lauro C. (2005) PLS Path Modeling. Computational Statistics \& Data Analysis 48, 159-205.

Tzeng HM, Ketefian S \& Redmean RW (2002). Relationship of nurses' assessment of organizational culture, job satisfaction, and patient satisfaction with nursing care.

International Journal of Nursing Studies 39, 79-84.

Van den Bosch R \& Taris TW (2013) Authenticity at Work: Development and Validation of an Individual Authenticity Measure at Work. Journal of Happiness Studies DOI 10.1007/s10902-013-9413-3 (accessed 05 April 2013).

Vandenburghe C, Michon R, Tremblay M, Bentein K, Chebat JC \& Fils JF (2007) An Examination of the Role of Perceived Support and Employee commitment in EmployeeCustomer Encounters. Journal of Applied Psychology 92, 1177-1187.

Wetzels M, Odekerken-Schroder G \& Van Oppen C (2009) Using PLS path modeling for assessing hierarchical construct models: Guidelines and empirical illustration. MIS Quarterly 33, 177-195.

Wharton AS (1993) The Affective Consequences of Service Work: Managing Emotions on the Job. Work and Occupations 20, 205-232.

Williams J \& Stickley T (2010) Empathy and Nurse Education. Nurse Education Today 30, 752-755.

Wright TA \& Cropanzano R (2000) Psychological Well Being and Job Satisfaction as Predictors of Job Performance. Journal of Occupational Health Psychology 5, 84-94.

Yang FH \& Chang CC (2008) Emotional labour, job satisfaction and organizational commitment amongst clinical nurses: A questionnaire survey. International Journal of Nursing Studies 45, 879-887. 


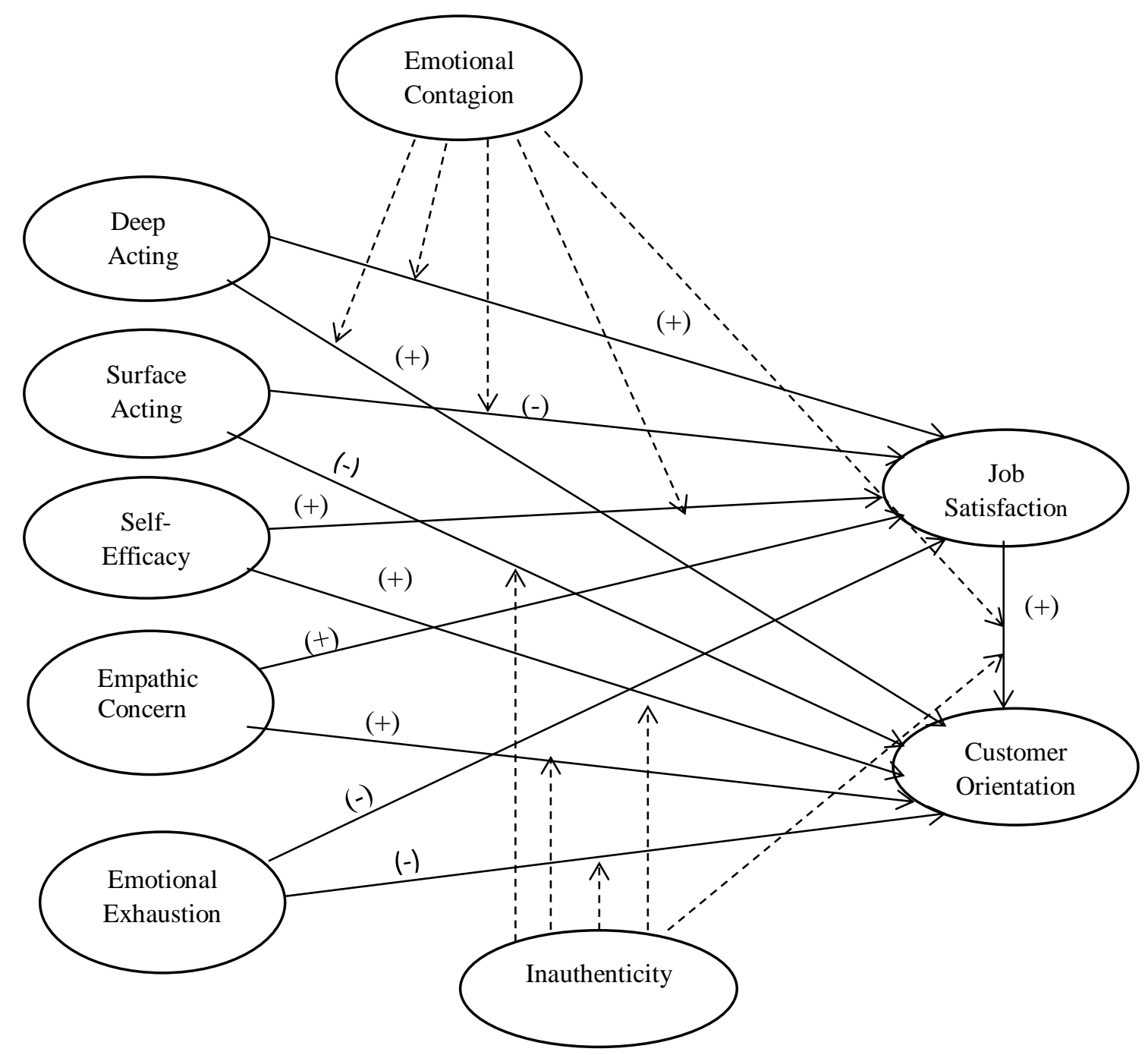

Figure 1: The Conceptual Model 


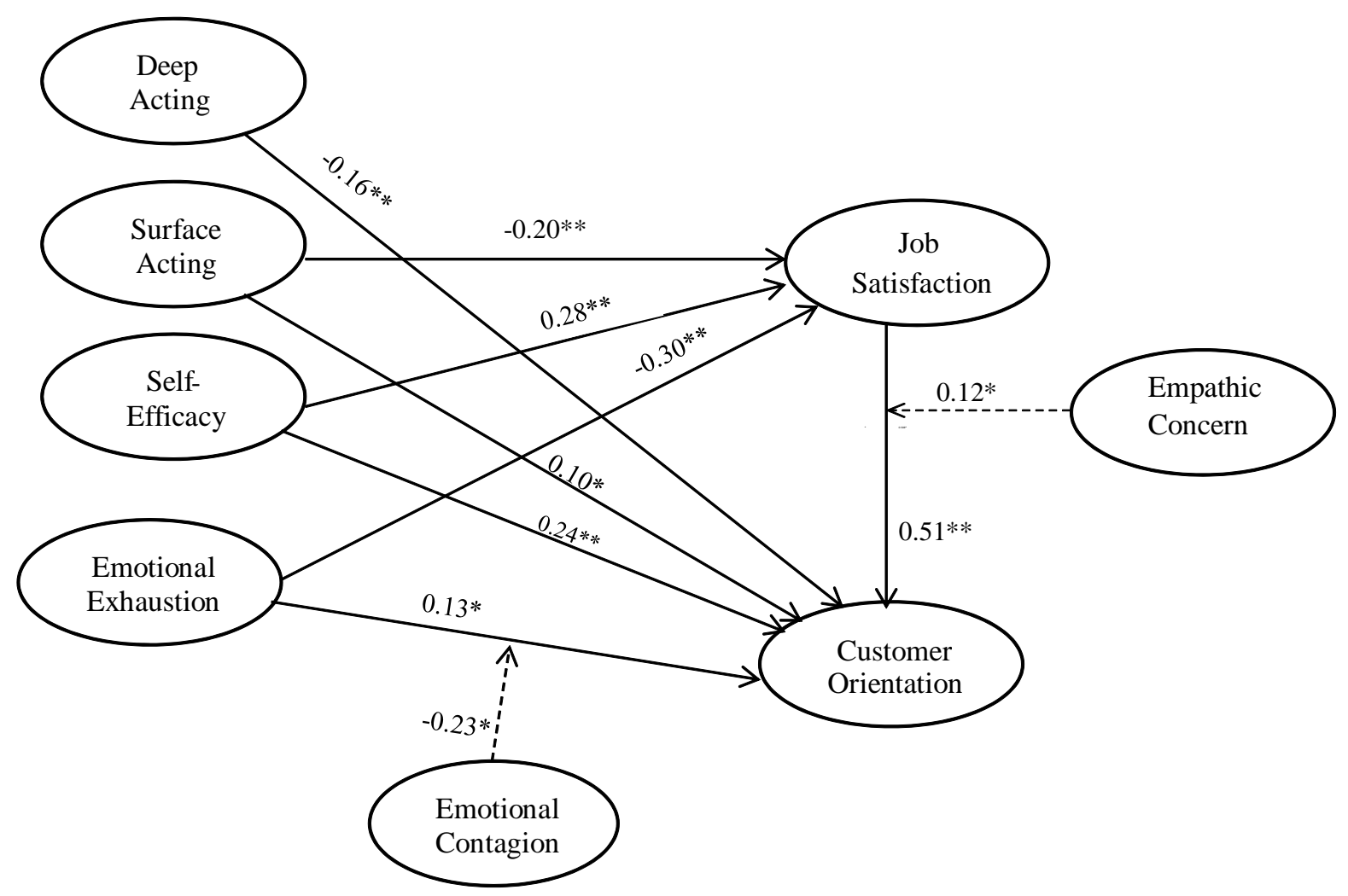

Figure 2: The Final Model 
Table 1: Means, Standard Deviations, AVE Scores, Composite Reliability, Cronbach's Alpha and Correlations

\begin{tabular}{|c|c|c|c|c|c|c|c|c|c|c|c|c|}
\hline Variable & M & $\mathrm{SD}$ & $\mathrm{CR}$ & $\mathrm{CA}$ & AVE & DA & SA & SE & EMPC & EmotC & $\mathrm{EE}$ & JS \\
\hline Deep Acting & 2.97 & 1.43 & 0.78 & 0.93 & 0.94 & & & & & & & \\
\hline Surface Acting & 3.86 & 1.16 & 0.88 & 0.65 & 0.74 & $0.28 * *$ & & & & & & \\
\hline Self-Efficacy & 3.25 & 1.51 & 0.92 & 0.72 & 0.51 & -0.15 & $-0.27 * *$ & & & & & \\
\hline Empathic concern & 5.27 & 0.92 & 0.90 & 0.73 & 0.51 & -0.03 & -0.12 & -0.03 & & & & \\
\hline Emotional contagion & 3.63 & 0.93 & 0.91 & 0.79 & 0.54 & -0.15 & -0.09 & -0.15 & $0.29 * *$ & & & \\
\hline Emotional Exhaustion & 3.69 & 1.19 & 0.94 & 0.83 & 0.55 & $0.19^{*}$ & $0.43 * *$ & $-0.25^{* *}$ & 0.03 & $0.17^{*}$ & & \\
\hline Job satisfaction & 5.23 & 1.18 & 0.96 & 0.83 & 0.59 & -0.15 & $-0.39 * *$ & $0.47 * *$ & $0.16^{*}$ & $0.20 *$ & $-0.48 * *$ & \\
\hline Customer orientation & 6.49 & 0.71 & 0.99 & 0.91 & 0.75 & $-0.20 *$ & -0.14 & $0.45^{* *}$ & $0.30 * *$ & $0.17^{*}$ & -0.15 & $0.58 * *$ \\
\hline
\end{tabular}

** sig. at $.01, *$ sig. at .05 . 
Table 2: PLS Modelling Analysis Results

Initial Model

Path

Deep Acting -> Job Satisfaction

Surface Acting -> Job Satisfaction

Self-Efficacy -> Job Satisfaction

Emotional Exhaustion -> Job Satisfaction

Deep Acting -> Customer Orientation

Surface Acting -> Customer Orientation

Self-Efficacy -> Customer Orientation

Emotional Exhaustion -> Customer Orientation

Job Satisfaction -> Customer Orientation

Emotional Contagion*Emotional Exhaustion

Empathic concern*Job Satisfaction
Path Sig. Path Sig.

Coefficient Coefficient

$\begin{array}{rrrr}0.03 & 0.36 & 0.03 & 0.36 \\ -0.20 & 0.01 & -0.20 & 0.01 \\ 0.28 & 0.01 & 0.28 & 0.01 \\ -0.30 & 0.01 & -0.30 & 0.01\end{array}$

$-0.17 \quad 0.01$

$-0.16 \quad 0.01$

$0.13 \quad 0.04$

$0.10 \quad 0.04$

$0.24 \quad 0.01$

$0.13 \quad 0.04$

$0.51 \quad 0.01$

$-0.23 \quad 0.02$
-0.12

$0.12 \quad 0.02$

$\mathrm{R}^{2}=0.40$

$\mathrm{R}^{2}=0.52$ 